\title{
¿A qué se refiere la palabra «imaginario»?
}

\author{
Eric Landowski \\ (Centre National de la Recherche Scientifique, Francia)
}

Recibido: $24 / 4 / 2013$

Aprobado: 19/5/2013

\begin{abstract}
Resumen: Tal como la palabra española «imaginario», imaginaire en francés (como immaginario en italiano e imaginary en inglés) es actualmente empleada de modo frecuente no solo como adjetivo sino también como sustantivo. Sin embargo, las complejas significaciones técnicas que adquiere en los trabajos de autores tales como Sartre, no serán consideradas en el presente artículo. El análisis enfoca sus usos no teóricos en un conjunto de ocurrencias halladas hoy en la prensa francesa. Dos diferentes significaciones son alternativamente asociadas al término. En algunos contextos, sustituye a «cultura» y designa una colección de estereotipos figurativos. En otros, es un equivalente de «imaginación», e imaginario se convierte en un poder creativo que, subvierte los clichés a los que la definición previa se refiere. El artículo expone la dialéctica entre esas dos facetas complementarias aunque también conflictivas de la noción de «imaginario».
\end{abstract}

Palabras clave: Imaginario-cultura / imaginario-imaginación / configuraciones / cultura / imaginario / estructuras

\section{What does «imaginaire» stand for?}

Авsтract: Unlike the English word «imaginary», imaginaire in French (like immaginario in Italian) is nowadays frequently employed not just as an adjective but also as a substantive noun. However, the complex technical meanings which it endorses in the works of such autors as, for example, Sartre, will not be considered in the present article. The analysis focuses on its theoretical uses in a sample of tokens found in today's French press. Two very different meanings are associated with the term. In some contexts, it stands for «culture» and designates a collection of figurative stereotypes. In others, it is an equivalent of «imagination», and imaginaire then becomes a creative power which subverts the very clichés to which the previous definition refers. The article explores the dialectics between these complementary although conflictive facets of the notion.

Keywords: Imaginaire-culture / imaginaire-imagination / configurations / culture / imaginaire / structures 


\section{Ut cultura imaginarius}

$\mathrm{E}$ 1 tratamiento teórico de «lo imaginario» no es algo obvio, en todo caso no lo es para un semiótico de nuestra especie. La palabra misma nos resulta casi extraña. Si hemos llegado a hacer uso de ella, es más que todo de un modo alusivo y por una suerte de facilidad de lenguaje. Perteneciente a un registro de vocabulario de aspecto sapiencial, es al mismo tiempo, habitualmente, vaga a propósito de lo que designa. Un vocablo de ese género ofrece, en efecto, todas las comodidades; es una verdadera palabra comodín por la que pasa todo. Por supuesto que hay excepciones. Hay un pequeño número de autores que no escriben como todo el mundo -Sartre o, por ejemplo, Althusser, y algunos otros que nos son menos familiares-, para los cuales invocar lo imaginario no tiene nada de alusivo. Para ellos, el término remite a conceptos rigurosamente articulados. Empero, como en casos semejantes, esos conceptos, por definición, son solidarios de las construcciones teóricas que los ponen en marcha y de las cuales extraen su pertinencia, no son trasladables tal cual de una a otra teoría. Para hacerlos compatibles habría que reformularlos.

Pero sucede que en nuestro entorno nadie se ha preocupado ni de conceptualizar eso que el sustantivo «imaginario» recubre en sus empleos más ordinarios ni de reelaborar semióticamente ninguna de las conceptualizaciones ya existentes a las cuales hacemos alusión, ni, aún menos, de tomar el término en cuestión como denominación de algún nuevo concepto específicamente semiótico. En consecuencia, no hay ningún lugar para él en el metalenguaje de la semiótica -en todo caso, de la que nosotros practicamos-. Ni siquiera figura entre las entradas del Diccionario de Greimas y Courtés. Sin embargo, eso no es suficiente para convertirla en una palabra tabú, tanto menos si hay motivos para preguntarse por las razones de esa ausencia. ¿Será que esa ausencia se debe a cierta incompatibilidad entre la teoría y lo que la palabra tiende a evocar en sus usos más corrientes? ¿Hay un desacuerdo con lo que designa en los usos más eruditos? ¿O bien la noción misma no sería pertinente en relación con la perspectiva general del Diccionario? Pues, por otro lado, ¿no se podría decir que, a pesar de todas las restricciones que preceden, la descripción y la comprensión del «imaginario humano» habría constituido el objeto mismo de todo el proyecto de Greimas y de sus sucesores?

Se constata una paradoja análoga a propósito de la Cultura -de preferencia con $C$ mayúscula-, otra palabra de buen tono que se presta a recubrir casi todo lo que se quiere, desde el gran mito fundador hasta la manera de plantar las coles, dejando mucho por decir. Todas las creencias, todos los conocimientos, las artes y las técnicas de todos los órdenes, todas las instituciones, todas las prácticas so- 
ciales y sus productos, y mil cosas más, desde las más nobles hasta las más humildes, nada deja de estar bajo la acogedora morada de la «cultura». Habiéndose lanzado una bella mañana a la exploración de los tesoros que contiene, Bouvard y Pécuchet no han regresado aún... Es cierto que la palabra tiene, sin embargo, su entrada en el Diccionario -no el de las Ideas recibidas, según Flaubert- sino el de semiótica (Greimas 1979: 77-78). Pero solamente con una pequeña $c$, a título bien preciso, bastante técnico y enteramente modesto: como uno de los polos de la categoría naturaleza/ cultura (situada sobre el mismo plano que la categoría vida/muerte), es decir en cuanto metatérmino descriptivo y no en cuanto denominación de un concepto teórico que vendría a sustituir las acepciones usuales del término por un contenido «científico». Lo que quiere decir que Cultura, como vasta cobertura, es, grosso modo, a la teoría semiótica de Greimas lo que la necedad era a Monsieur Teste: no era su fuerte; y que nosotros, greimasianos que en él nos inspiramos, somos incultos sin vergüenza, por lo que el vigoroso tanto como riguroso eslogan de los bellos años pre-68 conviene a maravilla: "Cuando oigo la palabra Cultura, con una gran C, saco mi revólver» (Landowski 2011).

No obstante, y esta es la paradoja, si no la contradicción, desde el punto de vista epistemológico, la semiótica de Greimas, por oposición a la de Peirce (y, salvo error, a la de Lotman), se si- túa en una perspectiva antropológica enteramente vuelta hacia las funciones del «espíritu humano» tales como se pueden aprehender analizando sus manifestaciones, es decir, precisamente las culturas. Al punto de que la naturaleza, así como lo real del sentido común, una vez rebautizados como «mundo natural», son considerados como dos artefactos entre otros, construidos por las mencionadas culturas. En el interior de ese marco, los objetos de nuestros trabajos empíricos surgen por ejemplo de la literatura o del deporte, de la moda o del derecho, de la arquitectura o simplemente de las formas de la vida cotidiana, explorando por turno (aunque sin plan premeditado -detalle que impide confundirnos del todo con los dos personajes de Flaubert-) todos los tipos posibles de producciones y de prácticas significantes a través de las cuales las comunidades humanas reconfiguran el mundo para hacer de él un universo dotado de sentido y de valor. ¿De qué queremos rendir cuenta si no es de aquello que ordinariamente llamamos la cultura, con o sin mayúscula?

Ahora bien, ¿en qué medida podemos esperar que lo que vale para la «cultura» valga también para el «imaginario», dando por entendido que las dos nociones no están sin relacionarse? A priori, las prevenciones de un semiótico de tendencia próxima a Saussure y a Hjelmslev son aún más fuertes frente a la segunda que frente a la primera, y no son enteramente las mismas. 
La noción de cultura, por poco operatoria que sea, depende, a pesar de todo, de un campo de reflexión socioantropológico donde un heredero de Saussure no se encuentra incómodo. La noción de imaginario, en cambio, está cargada de connotaciones psicologizantes que, para todo estructuralista, por poco ortodoxo que sea, están radicalmente fuera de propósito. $\mathrm{Y}$, sin embargo, las cosas son menos tajantes. De hecho, la posición que la semiótica estructural ha adoptado desde sus inicios (con Semántica estructural) en relación con lo imaginario está marcada por contradicciones (a nuestro parecer más aparentes que reales). Estas son análogas a la que venimos destacando a propósito del estatuto que se atribuye a la «cultura». Al mismo tiempo que la pertinencia de ambas nociones es denegada sobre el plano teórico y a título de instrumento operatorio, lo «cultural» constituye su campo específico, en el plano epistemológico, y prácticamente su único terreno en términos empíricos. Lo que quiere decir que la semiótica greimasiana es, en el fondo, una «semiótica de la cultura», aunque tenga sus razones para no autodefinirse como tal. Asimismo, podría ocurrir que fuera, desde un punto de vista más general, una semiótica del imaginario, pero que, en parte por las mismas razones, en parte por otras, no tendiese a hacer de una fórmula tal su marca de fábrica.

En breve, antes de toda otra consideración más detallada, para nosotros «lo imaginario» es una no- ción casi inevitable y una palabra que preferiríamos evitar. El balance entre ese pro y ese contra crea todo el problema. Comencemos por la pars destruens: ¿por qué querer evitar la palabra?

\section{Pars destruens}

Ante todo, porque las palabras, independientemente de lo que significan -tal vez, incluso antes de tener sentido- tienen un valor. En esa perspectiva, su condición no es la misma que la de las personas. En la vida social, como se sabe, si el valor atribuido a cada uno fluctúa, es en buena parte en función de las relaciones que se sostienen, honoríficas o comprometedoras, y en nuestros días, más especialmente, en función de las «redes» a las cuales uno se afilia (células, partidos, gremios, grupos). Las buenas redes hacen las buenas reputaciones; las «malas juntas» lo hacen a uno infrecuentable. Las palabras también pueden ser sorprendidas en mala compañía, en malos contextos, o como se dice en retórica, en malos «lugares». Empleada «a diestra y siniestra», una palabra se devalúa, se «prostituye» y a la larga termina por ser inempleable.

«Imaginario», desde ese punto de vista, es un término que da prueba de una formidable resistencia a la usura. Habiendo adquirido, si se puede decir, sus títulos de nobleza sirviendo bajo la pluma de autoridades intelectuales prestigiosas, hoy desaparecidas (entre otras, las mencionadas más 
arriba), goza de tal aura que, de cualquier manera, todo se le permite. Para formarnos un juicio, hemos extraído durante algunos meses, principalmente setiembre y octubre del 2010, un gran número de ocurrencias del término aparecidas en un conjunto bastante diversificado de periódicos parisienses (Le Monde, Les Echos, Le Figaro, Le Parisien, La Terrase, Telérama, e incluso Libération). Esa extracción, cuidadosa aunque no sistemática, nos ha permitido recoger una cincuentena de ocurrencias, a las cuales han venido a añadirse algunas otras, una docena, que forman un conjunto aparte, el cual hemos encontrado de manera casi aleatoria al hilo de nuestras lecturas o relecturas semióticas del momento. ${ }^{1}$ Las constantes que se han observado en la parte periodística de ese «corpus», y de las que se encuentran ciertos rasgos en algunos semióticos representantes de la otra parte, son de dos órdenes: sintáctico y semántico.

\section{¿El imaginario de quién, de qué?}

Sintácticamente hablando, se constata que el lexema «imaginario», como sustantivo, aparece raramente en un enunciado sin que paralelamente sean colocados, en general de manera explícita, dos actantes que constituyen sus funtivos indispensables. En primer lugar, un actante Sujeto, a veces figurado por un individuo, a veces por una colectividad, sin límite de tamaño: imaginario «de Bernanos» o de mi vecino de apartamento, «de la joven generación» o de la humanidad entera, poco importa, el imaginario es siempre el de alguien, quien sea, al límite, el de una entidad abstracta más antropomorfizada: ese es el caso en Sémiotique des passions, no del imaginario de los autores, como se podría esperar, sino del «imaginario de la teoría». Enseguida, y lo más frecuente, un actante Objeto, porque el imaginario es ordinariamente presentado como un imaginario de cualquier cosa: de la política o del viaje, del sexo o de la guerra, etcétera. Planteada así, la elección está enteramente abierta.

Esas dos variables tienen, naturalmente, vocación de combinarse y se obtiene un sintagma-tipo de la siguiente forma:

imaginario / de quién / de qué

1 Ese extracto complementario incluye principalmente CNN et la mondialisation de l'ímaginaire de Andrea Semprini (París, CNRS, 2000), las páginas de Francesco Casetti sobre "Cinéma et imaginaire" en Les théories du cinéma depuis 1945 (París, Nathan, 1999); de Greimas Sémantique structurale (París, Larousse, 1966), la introducción a Des dieux et des hommes (París, PUF, 1985) y la primera parte de Sémiotique des passions (París, Seuil, 1991); un artículo de Jacques Geninasca, “Les acquis et les projets" (Nouveaux Actes Sémiotiques, V, 25, 1993); y accesoriamente, vistas las facilidades de marcaje lexical que ofrece la computadora, algunos de nuestros propios trabajos recientes. 
Ejemplo:

«el imaginario de Bernanos

a propósito de la política»

Sea, en estilo sapiencial:

Iso

$\mathrm{O}$, más legible pero equivalente:

«el imaginario político de Bernanos»

Dado que en la naturaleza de un modelo de este género no hay reglas de restricción concernientes a la elección de las variables, se puede ad libitum hacer variar el valor de $S$, o de $O$, o de las dos a la vez y obtener así un número indefinido de enunciados que presentan la ventaja de ser todos gramaticalmente correctos, aunque puedan aparecer unos más convencionales y otros más excitantes por su novedad:

«el imaginario político de Bernanos»

«el imaginario político de los franceses»

«el imaginario gastronómico de los franceses»

«el imaginario gastronómico de los ingleses»

La combinatoria es potencialmente tan ilimitada que se puede ver ahí, al escoger, un procedimiento de genera- ción automática de temas de tesis para estudiantes (o profesores) a falta de inspiración o, lo que viene a ser casi lo mismo, el principio de un juego de sociedad (cf. infra, anexo) al estilo de la primera etapa de Umberto Eco (1992).

\section{Los dos imaginarios}

De los funtivos pasamos ahora a la función, o si se prefiere, al predicado, «el imaginario» mismo, y veremos qué regularidades de empleo presenta desde el punto de vista de sus investimientos semánticos. ¿«De qué el imaginario es nombre?», como diría Alan Badiou (2007: 160). Según parece, de dos realidades semióticamente bien distintas. Si se toma por criterio el tipo de configuración que recubre esa palabra, el corpus se divide, en efecto, de modo casi igual, en dos clases de ocurrencias. En una, designa cierta manera de configurar el sentido; en la otra, casi su contrario. Desde ese punto de vista, el lexema «imaginario» se asemeja mucho a eso que en lingüística árabe se llama un «addad» (Greimas 1966: 58 [1971: 88]; Cohen 1961).

\section{El imaginario lq}

Ante todo, en un gran número de casos, lo que se llama «el imaginario» se presenta como una suerte de gran cajón en el que se encuentran almacenadas las cosas más heteróclitas, cosas que todo el mundo conoce y que, no perteneciendo propiamente a nadie, 
son bienes de todo el mundo: un «patrimonio común». La expresión tipo es «En el imaginario de $\mathrm{S}$, se encuentra $\mathrm{O}$ »:

En el imaginario francés, se encuentran el General de Gaulle y François Mitterrand [...]. Su aura trasciende los hitos [...]. François Mitterrand pertenece al patrimonio común (F.-X. Bourmaud, Le Figaro, 11 de octubre del 2010: 2).

Pero se encuentran también O1, O2... On, es decir, por ejemplo, para atenernos a lo que antes evocábamos, «la guerra», «el sexo», «la política», «el viaje». Y tutti quanti:

En el imaginario colectivo, las palomas son indisociables del Air du Temps de Nina Ricci (C. Briard, Les Echos, 8-9 de octubre del 2010: 15).

[...] hemos aprendido con Dolto que nuestro infante es una persona. En nuestro imaginario, está, por consiguiente, a la vez pequeño, en crecimiento, y ya grande (P. Serk, Le Figaro, 20 de septiembre del 2010: 12).

Dado que no pueden, a decir verdad, ser contenidos en el receptáculo del imaginario ni las cosas ni las personas ni los hechos mismos considerados componentes de dicho patrimonio sino a lo más su imagen, en cuanto continente se parece menos a un cajón de tesoros que a un álbum de imágenes, algunas fijas, la mayor parte animadas como pequeños vídeos mentales. Lo que contiene esa «videoteca» virtual es, por consiguiente, un patrimonio icónico. Ahí se mezclan, entre otras, siluetas de gentes célebres y evocaciones de escenas memorables:

En Francia, el filósofo es una figura familiar. Nuestro imaginario colectivo asocia cada pensador a una obra teórica, pero sobre todo a una presencia encarnada [...] el cuello vuelto de Michel Foucault, los pantalones raídos de Gilles Deleuze, los sacos de terciopelo rayado de Jacques Derrida o los trajes de lana de Claude Lefort [...]. Tantas imágenes que nutren las biografías de los grandes nombres de la filosofía (J. Birnbaum, Le Monde des livres, 8 de octubre del 2010: 1).

El 4 de agosto de 1789, primera de las 'grandes veladas' [...] noche que vio la desaparición del Antiguo Régimen [...], una de las escenas fundadoras sobre las cuales se construyó la identidad de Francia [...]. Momento inaudito que todavía impregna profundamente el imaginario político francés (J. Gautheret, Le Monde, 4 de agosto del 2009: 12).

Colección de figuras, de cuadros, de escenarios familiares a disposición de todos en el interior de un grupo social más o menos extenso, suerte de «museo imaginario», pero más ecléctico y más dinámico que el de André Malraux, el «imaginario» así concebido es, en el fondo, semióticamente hablando, el componente figurativo de una «cultura». Sucede, por lo demás, que los dos términos parecen conmutables, como si el primero no fuese otra cosa que el doble del segundo: 
[...] se trata de sacar a luz las mutaciones que afectarán la cultura [io el imaginario?] de la guerra, es decir, el lugar que ocupa en el imaginario [ ¿o en la cultura?] de los contemporáneos (A. Lilti, Le Monde des livres, 8 de octubre del 2010: 7).

La estetización de la naturaleza [...] depende de los accidentes del imaginario colectivo [¿o de los caprichos de la cultura?] [...]. El paisaje: un universo mediatizado por palabras y por imágenes, interpretado por medio de arquetipos [io por arquetipos del imaginario?] (R. Debray, Le Monde des livres, 19 de mayo de 1995: IX);

\section{... o al menos su parasinónimo:}

Los Bandidos de Schiller y todo el imaginario romántico hacen del hombre marginado la encarnación trágica de la rebeldía individual. De esa cultura [¿o de ese imaginario?] del crimen, el manuscrito de T. Gueullette ofrece un bello ejemplo (D. Kalifa, LibérationLivres, 16 de setiembre del 2010: VII).

La tauromaquia forma parte de la cultura [¿o del imaginario?] que me anima [...]; cuando los toros me vienen al espíritu [...], el imaginario y un cierto arte de vivir me vienen al espíritu (F. Marmande, citando al ministro de Agricultura, Le Monde, 8 junio del 2001: 29).

Por consiguiente, a esa forma de imaginario convenimos en llamarla el imaginario-cultura, Iq.

Para que los ítems que contiene sean fácilmente memorizables y puedan servir de referencias reconocibles y utilizables por gran número de personas, es preciso que estén a la vez netamente dibujados, suficientemente simples en su forma y estables en el tiempo. El género de imágenes que tienen su lugar en el «imaginario colectivo» en cuanto patrimonio colectivo se precisa entonces: son otros tantos clichés.

Cuando esos clichés se constituyen en macrounidades figurativas bastante fijadas para poder migrar tales cuales, en bloque, en relatos diferentes (a la manera de eso que los folcloristas llaman «motivos») (Greimas-Courtés 1979: 238-239), se habla con frecuencia, más precisamente, de «imaginería»:

Espartaco: Sangre y Arena [...] enésima saga del héroe hecho en la Antigüedad [...]. La representación de los combates de gladiadores corresponde a una imaginería fantasmática heredada de los últimos siglos. Es un producto formateado del que la ideología nativa e imaginería exhibicionista darán buena conciencia a todos los que, desde la Revolución francesa, han refaccionado la Roma antigua a la voluntad de sus fantasmas (Cl. Aziza, Libération, 18 de octubre del 2010: 33).

Banderas y corderos. Gritos de guerra y balidos. El fin del espectáculo, Seguirán mil años de calma desafía la imaginería bíblica de paz (R. Boisseau, Le Monde, 7 de octubre del 2010: 23).

El universo de Lynch se declina en varios registros culturales, lo que lo hace asimilable por todos los vanguardistas prescriptores, desde los 
partidarios [...] del fetichismo de buen tono [...] hasta los apasionados de la imaginería teen-pop regresiva (D. Vezygrolou, Libération, 15 de octubre del 2010: 30).

En cuanto repertorio de clichés y de motivos, el imaginario-cultura es un continente de dimensión infinitamente extensible y cuyas paredes porosas están hechas para permitir de tiempo en tiempo la entrada de cualquier figura nueva:

El sociólogo Jean-Louis Fabiani analiza el lugar singular del filósofo en el imaginario colectivo de los franceses [...]. ¿Podemos fijar la fecha del nacimiento de ese héroe en el imaginario francés? (J. Birnbaum, Le monde des livres, 8 de octubre del 2010: 8).

En su época, Jean-Paul Belmondo era un arquetipo muy nuevo en el imaginario. Un hombre joven bastante villano, con una nariz rota, pero un icono de la Nueva Ola (O. Delcroix, Le Figaro, 16-17 de octubre del 2010: 30).

El corpus no dice nada sobre las condiciones de acogida de un «arquetipo» inédito. ¿El recién llegado se añade simplemente a las figuras ya emplazadas? ¿No será que expulsa a una de ellas para sustituirla? ¿O bien su integración entraña una reestructuración del conjunto? Si la cuestión de una historia del imaginario-cultura, o al menos (mucho más restrictivamente) de tal o cual de sus elementos considerado aisladamente, es por consiguiente planteada, nada en cambio es pensado acerca de su organización eventual en cuanto conjunto estructurado. Tomémoslo, pues, también nosotros por lo que el estado actual de los conocimientos parece ser, a saber, una colección no ordenada de referencias puntuales; aún si cada una de ellas puede conducir a todas las demás, como en un diccionario de la lengua, o en una enciclopedia.

Pero cabe oponer los dos tipos de inventarios: si un diccionario define el sentido de las palabras y si una enciclopedia explica el contenido de las nociones propias de un estado de las ciencias, de las artes y de las técnicas, el imaginario, por su parte, no dice la verdad de las cosas, aunque lo pretenda. Y no puede decirla dado que las verdades que enuncia son relativas a simulacros que él mismo instituye como un «trozo de imaginario»:

El Sur parece ser una región de los Estados Unidos. Se trata de un trozo de imaginario, de una comarca hecha de palabras. Sus constructores se llaman Faulkner, Capote, McCullers» (E. Neuhoff, Le Figaro litteraire, 28 de octubre del 2010: 4).

Eso resulta particularmente de un número apreciable de ocurrencias, donde el imaginario tal como acaba de ser descrito -el imaginario-cultura- es evocado en cuanto tejido de prejuicios consolidados al hilo del tiempo, de certezas puramente «imaginarias» (el término es tomado esta vez como adjetivo), por consiguiente, falaces y tanto más perniciosas cuanto que son ampliamente compartidas: 
¿Qué es un nómada? [...]. Al hilo de los siglos, en torno a figuras de la errancia, el imaginario europeo ha multiplicado los temores [...]. Aquel que no hace más que pasar, con seguridad que es un malhechor. ¿Qué hacer con esos prejuicios? (R.-P. Droit, Les Echos, 15 de setiembre del 2010: 17).

En todos estos casos, «el imaginario»-el imaginario-cultura- se presenta como una instancia propiamente sociosemiótica, como una institución difusa a cargo del universo de sentido socialmente aceptado, de su gestión, de su «formato»y de su propagación como sentido común. $\mathrm{Y}$ «el imaginario» es el nombre de esa institución, o de esa «instancia». Por todas esas características, se opone a otra configuración semiótica que sería más bien figura de una instancia antiinstitucional por excelencia, aunque lleva el mismo nombre de «imaginario».

\section{El imaginario li}

Hay, por consiguiente, un imaginario número dos. Para marcar bien su diferencia en relación con el imaginariocultura, Iq, lo bautizaremos imaginario-imaginación, Ii.

De ese modo, «imaginación» viene a ocupar el lugar de «cultura»: sustitución ciertamente algo extraña, pero que impone el análisis del corpus. Mientras que el imaginario era asimilado a eso que hemos llamado el componente figurativo de una cultura, la imaginación no podía encontrar ahí ningún lugar. Por definición, puesto que un repertorio que contiene todo lo que hay que saber y todo lo que es suficiente creer para vivir bien no pide otra cosa que la memoria. Al promover la reproducción de lo mismo -la recitación en el discurso, la repetición en las prácticas-, el repertorio, el ayudamemoria, el memento asfixian toda veleidad de invención y hacen de la imaginación una facultad superflua del espíritu, y hasta potencialmente peligrosa. En consecuencia, la imaginación no tenía ninguna razón para aparecer en $I q$. Ii, al contrario, reagrupa ocurrencias que la acogen, la solicitan, la estimulan, que hacen de ella la fuerza misma de otra forma del «imaginario»:

Andersen da rienda suelta a su fantasía [...]. Esa mezcla de géneros y cierta libertad abren el imaginario [...]. Hay que reivindicar un teatro de la imaginación, del sueño (G. David, La Terrase, octubre del 2010: 19).

Eso nos puede llevar lejos. Hasta un «burlesco descuajeringado y místico» (F. Dumonet, Le Monde des livres, 23 de setiembre del 2010: 5). Probablemente cualquier cosa de este género es lo que se encuentra en el último libro de Pascal Jardin puesto que esa novela -que, al parecer, «se dedica a reencantar cada día lo cotidiano»-, «hace estallar a los contadores del imaginario» (P. Vavasseur, Le Parisien, 26 de octubre del 2010: 37). O en la música de Karl Jannuska, celebridad del jazz 
cuya improvisada ejecución hace que los oyentes «se abran a maravillosos imaginarios» (S. Siclier, Le Monde, 23 de julio del 2010: 15).

En verdad, cuando una palabra vale sobre todo por su halo de misterio no conviene exigir demasiada precisión. Tratemos, no obstante, de abordar esa cosa extraña con la que se hace «estallar a los contadores» y de comprender con exactitud qué tienen de maravilloso esos imaginarios (en plural) a los cuales «se abren los oyentes». Con tal de que sea posible descifrar semejante jerigonza, parece que se trata, de nuevo, de dos cosas.

Primeramente, de una suerte de ayudante, de fuerza vital, de potencial energético salvador: "Jean Genet convoca el imaginario como un útil de supervivencia» (G. David, La Terrasse, octubre del 2010: 25).

Mientras que la configuración precedente del imaginario es una herencia intelectual petrificada en cuanto saber (o creer), el imaginario aquí «convocado» ha devenido, como en numerosas otras ocurrencias, una función dinámica y más precisamente un poder liberador y creador. El imaginario-cultura otorga un saber-vivir, de orden social, el imaginario-imaginación un poder-vivir, de orden existencial. Lo que implica que, al mismo tiempo que la función, los dos funtivos, $\mathrm{S}$ y $\mathrm{O}$, cambian también.

Formado de un conjunto de clichés destinados a servir de referencias, el imaginario-cultura era por naturaleza el bien de una comunidad, de un sujeto colectivo: Iqso. El imaginario-imaginación es siempre relativo a un sujeto individuado: $I i \Sigma o$.

No se trata ya del imaginario «de cualquier cosa», de un objeto particular y definido -unas veces esto, otras veces aquello (la política, la guerra, etcétera)- como sucedía en el caso anterior, sino de un Imaginario in absoluto: no sin objeto sino que el objeto, $\Omega$, no necesita ser especificado, ya que, como pura facultad, el imaginario está llamado a transfigurar todas las cosas.

Abreviando, de un lado, Iqso; de otro, $\operatorname{Ii} \Sigma \Omega$.

Esta nueva función, que tiene por consecuencia la apariencia de la intransitividad, interviene a la manera de una potencia a la vez generadora de sentido y regeneradora del Sujeto: «Creo que el imaginario nos autocrea sin cesar» (F. Dumontet, citando la novela de Vincent Ravalec, art.cit., Le Monde des livres, 23 de setiembre del 2010: 5).

¿De dónde proviene semejante potencia? El corpus indica dos orígenes posibles. Algunas veces, parece provenir de una instancia trascendente (en términos de gramática narrativa, de un «Destinador») que el sujeto «convoca» y que la otorga generosamente, como una gracia. Otras veces, esa misma potencia parece, al contrario, tener su fuente en algún lugar dentro del mismo Sujeto, puesto que gracias a ella, se nos dice, el sujeto se «autocrea», reflexivamente. Se trata, pues, 
en este caso, de una competencia (del orden del poder-hacer) que posee por adelantado y que se encuentra en estado virtual. Para que se actualice, hace falta que el sujeto «ponga lo suyo» con un esfuerzo -un «esfuerzo de imaginación»- que depende de la conciencia, por tanto, puramente «interior». Pero, al mismo tiempo, también con un trabajo. Porque está bien que la imaginación incida sobre cualquier cosa, pero esa cualquier cosa, en la ocurrencia hecha de imágenes o de figuras, no puede llegar al sujeto más que del exterior, de la cultura que lo rodea, dicho de otro modo, de Iq. Se comprende por eso que si la competencia en cuestión no es extraída del «patrimonio» socializado, institucionalizado, como ocurría anteriormente, su ejercicio lo presupone, a la vez porque es aquello con lo que la imaginación en acto permite que el sujeto se emancipe y porque es algo así como el zócalo, a partir del cual elabora sus propias «imágenes».

Al mismo tiempo que una fuerza interior dispuesta a trabajar, o que una gracia que cae del cielo, «imaginario» sirve también, en ese tipo de contexto, para designar el producto -la configuración-que se obtiene si uno «da rienda suelta a la fantasía», a saber, «otro mundo»:

El escritor rechaza los límites de lo posible. Su imaginario [Ii, como poder] hace variar las situaciones al infini- to [...]. Ese poder de anticipación no concierne únicamente al género de la ciencia ficción. Todo relato diseña los contornos de otro mundo [Ii como configuración] (J. Birnbaum, Le Monde des livres, 1 de octubre del 2010: 4).

Desde el punto de vista semiótico, ese mundo, por más que sea «otro», e incluso, si se quiere, el más desarticulado que se pueda concebir, no tiene sin embargo nada de «místico». Nada, en todo caso, de excesivamente misterioso. Es simplemente otro nivel de realidad construido, también, por discursos, verbales o en imágenes. Pero es, evidentemente, un nivel diferente, en cuanto a su contenido, del que diseñan los estereotipos del imaginariocultura. Dicho de otro modo, lo que distingue un «mundo» del otro no se debe a una diferencia de orden ontológico de tal modo que uno reflejaría «lo real» mientras que el otro se eximiría de hacerlo. Los dos imaginarios, $\mathrm{Ii}$, tanto como Iq, son sistemas de discursos que cumplen la misma función semiótica consistente en construir el mundo como universo significante. En consecuencia, la disparidad de estatuto concerniente a las configuraciones que instalan no se basa en una diferencia que afecte su relación con las cosas mismas, consideradas como datos. Es únicamente el resultado de las relaciones que se tejen entre ellas en cuanto sistemas de discurso. ${ }^{2}$

2 Razón por la cual, decir que «el imaginario reside en lo real» no nos parece ni muy esclarecedor, ni es suficiente añadir que «vemos lo real a través de él» (M. Butor). 
Uno de ellos, Ii, ignora los clichés, desinfla los lugares comunes, desprecia las verosimilitudes que el otro sostiene, instaurando, por lo mismo, un «otro real» donde lo que aparecía precedentemente como «los límites de lo posible» se encuentra «rechazado», sobrepasado: el imaginario-imaginación es, en su contenido, lo «inimaginado» -mejor, lo inimaginable - del imaginariocultura. Por eso el universo de sentido construido según $I i$ tiene razones para pasar por «sorprendente»: por su carácter transgresivo respecto de aquello que es visto como la manera «normal» o simplemente «banal» de hacer significar el mundo que nos rodea. Tampoco es necesario andar buscando no se sabe qué cualidad sui generis e inefable que le sería intrínseca y que haría de él un universo de otro orden. Basta con que «salga de lo ordinario».

Por lo mismo, no se puede esperar encontrar muchas ocurrencias de Ii en las páginas serias -políticas, sociales, económicas o financieras- de nuestros periódicos. Su lugar está esencialmente en los textos literarios y en los suplementos de espectáculos: no es un imaginario para los gestores de la sociedad. Para ellos, Iq es de sobra suficiente (tanto como necesario). Ii pertenece al grupo de los insatisfechos con el «pensamiento único», de los reinventores del mundo y de los creadores en todos los géneros -maestros de puesta en escena, escritores, saltim- banquis y hasta malabaristas- cuando tienen «ideas»:

Yo estaba en el malabarismo concreto, he pasado al malabarismo abstracto [...]. Esta creación ha comenzado con una pequeña idea. Con una hoja de papel. ¿Se puede hacer soñar a una hoja? ¿Se la puede investir gestualmente de un imaginario? (F. Roussel, reportaje con ocasión del 23. ${ }^{\circ}$ festival de circo, Libération, 25 de octubre del 2010: 32).

Más generalmente, este imaginario es el de todas las gentes un poco al margen, un poco poetas, un poco utopistas, el de los soñadores, especie en vías de desaparición -y con razón: ¡cuidado con el «celular»!-:

Esta maravilla tecnológica amenaza al imaginario ocupando subrepticiamente el lugar de los momentos de ensueño propicios a la creación [...]. No se aprende ya a estar solo y a soñar (M. Laronche, Le Monde, 5-6 de setiembre del 2010: 21).

\section{Dialéctica del imaginario}

Se ve, pues, cómo se articulan uno con otro los dos universos en cuestión. Iq sostiene el discurso canónico y autodenominado «realista» de las cosas entendidas. $I i$, impertinente por naturale$\mathrm{za}$, inventa alegremente otro universo, que, visto del lado opuesto, «sobrepasa los límites» (de la sana razón). ${ }^{3}$

3 Para el lado alegre de esta dialéctica, cf. Geninasca (2010). 
Entre esos dos universos, ¿hay lugar a escoger? Uno tiene la solidez de lo verosímil más incrustado en los espíritus; el otro, la ligereza irresponsable del fantasma que se asume como tal. Pero, en este punto, es preciso recordar aquello que decía Cyrano de Bergerac: «La luna, aseguraba, es un mundo como el nuestro, al que el nuestro le sirve de Luna» (Cyrano de Bergerac, en Prévot 1998). Eso va en paralelo con la relación entre los dos imaginarios, y más precisamente entre los «mundos»-los niveles de realidad-que ellos instalan: el fantaseado por el imaginario-imaginación es positivamente, como la luna, un «otro real», al que «el real», que se pretende único -construido y canonizado por el imaginario-cultura- sirve de fantasma.

Es, al menos, lo que deja entender un hombre responsable y serio (pero también, es verdad, un poco escritor -un poco «poeta»- a sus horas), el presidente Valéry Giscard d'Estaing:

No estoy seguro, confiesa en una entrevista, de que lo real sea único. Pienso que el imaginario existe, que está al costado, que camina... Y este otro real tiene la misma probabilidad que el primero (F. Gorin, Telérama, 20 de octubre del 2010: 170).

De ahí a invertir las prioridades no hay más que un paso:

El artista plástico libanés Walid Raad inventa los archivos de su país en guerra para construir una verdad explosiva [...]. Un sueño de arenas, y otra realidad-ficción, a la medida del imaginario [...]. (H. Bellet, Le Monde, suplemento Festival de otoño, 11 de setiembre del 2010: 6).

Contrariamente al imaginario estandarizado, que recubre el mundo con sus estereotipos de pacotilla, el imaginario $I i$, que camina «al costado», revela una realidad «otra», que, aunque está reconocida como del orden de la «ficción», es paradójicamente la que dice la «verdad»-y lo que es más, una verdad «explosiva»-. En el runrún bien programado de la cultura para el Sr. Todo-el-Mundo, la imaginación produce accidentes felices y estalla.

Al mismo tiempo, hemos encontrado eso que «hace estallar a los contadores del imaginario» Iq. Es simplemente Ii. Esta metáfora bizarra que habíamos tomado primero por gratuita y desnuda de sentido, se ve ahora que tiene su lógica. Se inscribe en el cuadro de una dialéctica de dos imaginarios, que conduce hasta en el detalle la elección de expresiones y de figuras utilizables para hablar de ellos.

Se oponen como el orden se opone a lo renovado, y viceversa. Esas dos realidades -perdón, esos dos imaginarios-interactúan, en el nivel narrativo, como los héroes de una confrontación multiforme y espectacular fundada en su antagonismo recíproco:

\section{Iqso versus $I i \Sigma \Omega$}

Unas veces es el imaginario-cultura el que humilla al imaginario-imaginación, buscando tenerlo encerrado en 
límites convenidos; otras, al contrario, es el imaginario-imaginación, fuerza de liberación, el que lucha por romper la argolla del imaginario-cultura:

Que un periodista suministre al lector lo que espera [según Iq] me parece dramático. Si las crónicas hacen emerger autores, obras nuevas, es porque así lo pide el imaginario [Ii, como potencia regeneradora] (J. Savigneau, Le Monde, 28 de agosto del 2010: 16).

Olvidando la imaginería jesuítica [fijada por Iq], el novelista François Sureau propone de su héroe [Ignacio de Loyola] una imagen inédita (S. Lapaque, Le Figaro litteraire, 14 de octubre del 2010: 5).

La tarea crítica de la historia no consiste en consolidar los estereotipos pasados [de Iq] sino en deshacerlos a fin de que emerja un imaginario político [Ii, como universo otro, más «verdadero», por tanto, «asombroso»] en el presente» (L- Jeanpierre, Le Monde des livres, 26 de junio del 2009: 8).

Pero esas relaciones conflictivas esconden una complicidad. Todo sucede como si el enfrentamiento se jugase sobre una escena:

[...] una escena teatral donde el discurso de la razón [según Iq] y el del imaginario [Ii] vinieran a medirse el uno con el otro antes de constatar que están unidos por un pacto secreto (J. Birnbaum, Le Monde des livres, 1 de octubre del 2010: 4).

¿En cuanto universo figurativo, a partir de qué materiales el imaginario- cultura podría, en efecto, construirse sino a partir de figuras que, antes de que no las haya transformado en estereotipos, han debido comenzar por ser producciones vivas del imaginarioimaginación?

Tal proceso de transformación puede ser asimilado a un reciclaje, pero supone, primeramente, operaciones de selección. El corpus nos da a conocer la existencia, interesante a ese respecto, de un Gran Premio del Imaginario concedido cada año por un jurado especial para «recompensar las obras de imaginación» (N. C. Ahl, Le Monde des livres, 30 de julio del 2010: 2). Ahí también se encuentra mencionada la célebre colección de Gallimard El Imaginario, específicamente «alineada de acuerdo con las construcciones de la imaginación» (V. Roy, Le Monde des livres, 23 de setiembre del 2010: 2). Esas dos instituciones de carácter casi oficial y de función enjuiciadora, especializadas en la evaluación de obras literarias, tienen por misión destacar entre las que pertenecen, de cerca o de lejos, al género «fantástico», las dignas de figurar en la biblioteca de un hombre culto (y puede ser, incluso, algún día, en los programas de enseñanza de la «gran literatura»).

Con eso, cumplen, una y otra, a la vez, dos misiones de orden público. En primer lugar, esa colección tanto como ese premio enriquecen el contenido del imaginario-cultura e integran en él, selectivamente, nuevos elementos venidos del imaginario-imaginación: 
ese es su rol explícito. Pero al mismo tiempo, por sus elecciones, las dos instituciones participan implícitamente (al lado de otras encargadas igualmente de la gestión social de la «cultura») en la definición de eso que es «el imaginario» desde el punto de vista de la cultura instituida. Y por esas instituciones, el imaginario es lo fantástico, a la vez en el sentido estricto del término, como género narrativo particular, y en el sentido usual de «extravagante», de extraordinario (respecto a lo ordinario de la «realidad»): el producto -original, inesperado, asombroso, bizarro- de una imaginación individual y creativa, la cual se considera que se ejerce fuera de toda restricción, a lo Hoffmann o a lo Borges, por ejemplo, por solo citar dos nombres que figuran en el catálogo de la colección Gallimard.

La imagen del «imaginario», tal como es institucionalmente (casi oficialmente) fijada en el imaginario-cultura, se reduce, entonces, a una sola de las dos facetas que le habíamos reconocido: la del imaginario-imaginación, Ii. La otra -la del Iq-, no tiene nada que ver. Dicho de otro modo, aunque lo propio del imaginario-cultura sea poder suministrar la imagen aceptada de cualquier cosa, hay, a pesar de todo, una cosa de la cual no da ninguna imagen: de sí misma. Y eso no tiene nada de asombroso porque un discurso que se toma por el discurso de la razón y el de la normalidad escapa necesariamente a sus propios ojos y no tiene ninguna razón (y sin duda tampoco los medios) de buscar distanciarse de sí mismo para «reflejarse» en su propia imagen.

El imaginario-cultura no depende menos del imaginario-imaginación, pues está en su origen y se alimenta de él recontextualizando sus productos, formateándolos, condicionándolos $\mathrm{y}$, de todos modos, predigiriéndolos. Pero esa dependencia es, de hecho, recíproca si se admite que, en sentido inverso, «la imaginación», la invención y el gusto mismo de inventar se enraízan en lo ya adquirido, en lo que está ya instituido, con ello y contra ello. Así, cada uno de los dos imaginarios suministra al otro la materia con la que trabaja.

Y, sin embargo, no están a la par. Iq e Ii no tienen semióticamente el mismo estatuto. El imaginario en el sentido Iq es la totalidad de figuras de las que una cultura dispone para representar el mundo. Ahora bien, en medio de esas figuras se encuentra, particularmente, entre mil otras, el cliché romántico del soñador-creador-transgresor de límites. Fijando, con la ayuda de ese simulacro, la imagen convencional del imaginario-imaginación en acto, el imaginario-cultura marca, de cierta manera, su primacía: es él, y no a la inversa, quien determina la forma de su «otro». Lo que plantea, al menos, dos cuestiones.

De una parte, ¿un dispositivo de ese tipo es exclusivo del universo conceptual de nuestra sociedad, o bien lo reencontramos, idéntico o bajo otras 
formas, en otros contextos? Sin duda, la noción misma de «imaginario», así como la articulación entre las dos formas que le conocemos, son productos singulares de nuestra «cultura» $-\mathrm{O}$, si se quiere, de nuestro «imaginario» contemporáneo-. Pero habría que volver a las encuestas comparativas para confirmarlo.

De otra parte, ise puede explicar semióticamente (o sociosemióticamente) a qué necesidad responde ese engendramiento de un imaginario por otro? A primera vista, instituyendo en su propio seno una figura ambivalente que asocia indisolublemente a la idea de creatividad la de extravagancia, el imaginario-cultura dispone de una figura palpable de su contrario que lo dispensa de justificarse: le es suficiente aparecer como el único espacio de valores seguros, que una «imaginación desbocada» no sabría, por construcción, asumir: lo "positivo», lo «sólido», lo «serio», lo «realista», lo fiable», lo «razonable».

Y esta convivencia entre un imaginario y el otro es tanto más eficaz cuanto provechosa desde los dos lados. Porque, en sentido inverso, el prestigio de los profesionales del imaginario $I i$ (los que reciben o solamente apuntan al «Gran Premio») descansa, en una parte esencial, en su propia disposición para endosar como una suerte de costumbre prêt-à-porter la imagen del "creador inspirado», sin otra guía que su propia inventiva, y, por eso mismo, consagrado a evolucionar al margen de la común y sana razón.

Así pues, en todos los planos, los dos imaginarios se presuponen mutuamente. Son los dos compadres de una sola y misma estrategia:

$$
\text { Iqso } \leftrightarrow \operatorname{Ii} \Sigma \Omega
$$

$Y$ al presuponerse se interdefinen. Tal como, más generalmente, se interdefinen los dos regímenes de sentido que, mirándolo bien, constituyen respectivamente sus manifestaciones particulares: un régimen del sentido programado, socializado, acantonado en la repetición de lo ya visto, ya conocido, ya dicho, frente a un régimen del advenimiento del sentido como accidente; el primero aplicado a estandarizar y a almacenar las innovaciones surgidas, bajo el modo de la «explosión» en el marco del régimen opuesto. ${ }^{4}$

Esas dos configuraciones que podrían inicialmente parecer heterogéneas -un «imaginario lleno de imágenes» [«imaginaire imagé»], fijado, instituido, que forma casi sistema y depende de una ciencia social, de las ideologías y de las representaciones, y un «imaginario creador de imágenes» [«imaginaire imageant»] que ape-

4 A propósito de la noción de regímenes de sentido y sobre su tipología, cf. Landowski (2005). 
laría a una filosofía de la conciencia o por lo menos a una psicología de los procesos de creación- no son, pues, finalmente, dos objetos sin relación, incomprensiblemente recubiertos por el mismo nombre. Forman estructuralmente una pareja cuyas relaciones son necesarias e inteligibles.

Ante esa pareja, ¿quién, en nuestros días, no trataría de tomar partido por $I i$, de juzgarlo más defendible, más «simpático» que Iq? ¿Es sin embargo más consistente que el otro? o bien ¿no se trataría simplemente de su doble, invertido? Si Iq es la expresión del conformismo cultural de una modernidad que ingenuamente confía en la razón (para quedar con Flaubert, a lo Homais), ¿se podría pensar que Ii no hiciera otra cosa que traducir un conformismo al revés (a lo Griboulle)?, propio de la «post-modernidad»: el de una contracultura que, para desmarcarse del «prêt-à-penser», dedica todo su imaginario a aquello que la imaginación puede tener de más delirante, de más «irracional», hasta el límite (paradoja esperada) de hacer de la sinrazón la forma misma de la razón.

«Imaginario»es, pues, claramente, un addad: designa al mismo tiempo una cosa y la cosa opuesta. O más bien, unas veces una, otras veces otra. Conmutable aquí con «cultura», más allá con «imaginación», deja a cargo del contexto la tarea de desambiguarlo. Y, de hecho, en la práctica, no existe nunca gran riesgo de engañarse. Pero si en el uso corriente decir «imaginario» equivale, prácticamente, desde el punto de vista sintáctico y semántico, a decir, según los casos, o bien «cultura» o bien «imaginación», ¿por qué escoger ese tercer término? ¿Qué añade con relación a los otros dos?

A priori, se podría pensar que su ambivalencia misma le confiere un carácter intrínsecamente tensivo que, solo por él, bastaría para justificar el favor que se le otorga. Lamentablemente, todo el presente análisis muestra que, desde que es puesto en contexto, cesa de ser equívoco y pierde todo ese carácter. Si su aura no se debe ni a la semántica ni a la sintaxis, es preciso que le venga de otra parte, y esa no puede ser otra que su pragmática.

De hecho, en primer lugar, «imaginario», vocablo más raro, más «rebuscado» que los otros dos, es paradójicamente más sapiencial que ellos aunque también más confuso. Es una palabra que, independientemente de lo que pueda, dado el caso, querer decir de «sorprendente» en un enunciado dado, es propicia en toda circunstancia para «asombrar» por su simple enunciación. Por sí solo, su empleo da testimonio de la alta competencia de aquel que lo usa. Porque nuestro «imaginario», a no ser que no pertenezca a nuestra «cultura», nos indica que quien dice «imaginario» tiene forzosamente, a falta de mucha imaginación, al menos una amplia Cultura. 
$\mathrm{Y}$, en segundo lugar, a diferencia de sus dos parasinónimos, que por comparación dicen bastante banalmente lo que «quieren decir» y nada más, permite, en cambio, por su vertiente alusiva, establecer una forma de complicidad con el enunciatario, lector o, en la conversación, con el interlocutor. Por eso, debe, si es posible, ser pronunciado con un tono grave y un aire de enterado: «El imaginario... sí, el i-ma-gina-rio, usted ve lo que quiero decir...». Habría que ser verdaderamente palurdo para confesar que no, que usted no «ve», completamente necio para pedir precisiones: el logos del imaginario es una comedia de lenguaje que se interpreta siempre entre dos y con jactancia por ambas partes.

Ninguno de esos aspectos nos parece suficiente para hacer de ella una palabra particularmente elegida para servir de metatérmino en una teoría.

\section{Pars construens}

¿Cómo pasar después de eso a la parte constructiva sin dar la impresión de que cambiamos súbitamente de opinión? «Reconstructiva» sería más apropiado... También en eso, confiamos ante todo en el corpus.

En otoño del 2010, un anuncio publicitario aparecido en Le Monde al momento del lanzamiento de un libro titulado Claude Lévi-Strauss. L'esprit des mythes, presentaba esa obra, y, en la misma ocasión, al antropólogo, de la manera siguiente, en cinco columnas:

Un año después de su desaparición, homenaje

A Claude Lévi-Strauss, matemático de lo imaginario

(Le Monde, 15 de octubre del 2010: 15)

«Matemático» - «de lo imaginario». La fórmula, sin ninguna duda, ha sido maduramente pensada por los servicios de marketing del editor (en la ocurrencia los de Le Monde; el libro formaba parte de sus «fuera de serie» a precio módico, «de venta en su quiosco de periódicos»). Y se ve bien a quién se dirige: a aquellos, probablemente numerosos, que lo leerán naturalmente como un oxímoron.

Porque, para volver a nuestro turno a la fórmula consagrada, «hay, en nuestro imaginario» (el imaginario q), a la vez un imaginario de las matemáticas, que imagina las matemáticas como el dominio de un rigor puro que excluye por completo la fantasía, el sueño, la invención, la imaginación, $\mathrm{y}$, como venimos de notarlo, un imaginario de lo imaginario que, en el polo opuesto, imagina lo imaginario como el dominio mismo de la fantasía, del sueño, de la invención, de una imaginación que ignora las leyes de la razón. Lévi-Strauss habría, pues, realizado la 
proeza de «matematizar» lo menos «matematizable» que puede haber, de reducir los rodeos y saltos de un pensamiento «irracional» al recto camino de la Razón.

Como esa presentación desfigura tanto las matemáticas -que, como todo el mundo sabe, no excluyen en absoluto la imaginación- cuanto el imaginario, que no se reduce al ejercicio fantasioso de la imaginación, se comprende que no se trata ahí, bastante demagógicamente por parte de un «gran periódico», más que de sorprender a aquellos a los que Greimas, en la introducción a su estudio de las mitologías lituanas, llamaba desdeñosamente los «aficionados a la mitología» (Greimas 1985: 11): aquellos prisioneros de la rejilla de lectura $I q / I i$, que reducen el imaginario a la imaginación más abracadabrante $\mathrm{y}$, aplicando esa rejilla a la lectura del «pensamiento salvaje», toman «los seres míticos por criaturas fantasiosas del imaginario humano» y los mitos mismos por productos, sin pies ni cabeza, de la imaginación» (Greimas 1985: 12).

Por cierto, ni Greimas ni incluso Lévi-Strauss han matematizado nada. Lo que uno y otro han logrado es dar cuenta en términos positivos, explícitos, racionales y rigurosos (por no decir «científicos»), de producciones humanas cuyo carácter a primera vista «descuajeringado» vale tanto como las elucubraciones de todas las vanguardias actuales, si es que no las superan. Partiendo del postulado de que ni los relatos mitológicos ni los dioses y los otros seres extraños que los pueblan son simples invenciones de una «imaginación desbocada», se han dedicado a despejar la forma de racionalidad que les es subyacente y que comanda su organización.

Semejante tarea solo tiene sentido a condición de suponer que la actividad del espíritu humano no se reduce ni a convocar los elementos dispersos de inventarios de figuras preconstruidas, ni, en el polo opuesto, a crear pieza por pieza figuras de fantasía desprovistas de toda relación entre sí. En consecuencia, si por alguna desconocida razón, un semiótico (o un antropólogo) debiera absolutamente tratar de describir el «imaginario» de una sociedad, de una obra, o de cualquier otra cosa (a no ser el suyo o el de su teoría), no se limitaría a poner de relieve uno a uno (tarea sin fin y además sin justificación) los ítems constitutivos de un repertorio de figuras asimilable a un imaginario-cultura, ni a localizar y coleccionar extravagancias y bizarrerías «inimaginables», contentándose con atribuirlas al imaginario-imaginación. Sería exactamente lo contrario: se interesaría no por las figuras tomadas una a una sino por sus relaciones, no por su relación con alguna «realidad» que se supone unívoca y que suele tomarse como criterio de evaluación del grado de racionalidad o de irracionalidad de las construcciones del espíritu; sino por las relaciones internas que las unen y por la manera como esas rela- 
ciones hacen sentido por sí mismas: en pocas palabras, se esforzaría por captar la lógica que, articulando en profundidad todos sus elementos, produce una visión del mundo que tiene su coherencia y su razón propias.

¿En realidad no es todo eso lo que precisamente unos y otros ya estamos haciendo? De eso dan testimonio dos tipos de estudios.

En primer lugar, aquellos, modestamente delimitados, que tienen por meta analizar la manera como se constituye y funciona en el interior de un universo de discurso determinado una noción o una figura particular cuya significación uno quisiera comprender. ¿Cómo, por ejemplo, el discurso de los medios construye la figura de la opinión pública y qué rol le atribuye en el relato de la vida política? O bien, ¿cómo la noción de generación, acompañada de figuras rodeadas de imágenes que le están asociadas (la «generación de antes de la guerra», la «generación pos-68», etcétera) sirven para la estructuración y para las estrategias del discurso social? O aun, ¿cuáles son los valores y las representaciones de la vida cotidiana a los cuales remite la puesta en escena, por el discurso en imagen de la publicidad, del consumo de una bebida como la cerveza? (Landowski 1989, 2004). Ese género de estudios monográficos permite extraer principios de organización del pensamiento que hacen inteligible la manera como una colectividad conceptualiza y figurativiza su propia existencia y su relación con el mundo. Decir que poniendo en evidencia tales principios se describe «el imaginario» -o, ¿por qué no, «la cultura»?- de los grupos sociales considerados sería sin duda más chic (a condición de reducir «el imaginario» al imaginario-cultura). Pero, a nuestro parecer, en el fondo no añadiría nada, a no ser un poco de confusión.

El otro tipo de contribución es más ambicioso y más necesario en la medida en que da verdadera respuesta semiótica a la construcción mitificante y mistificante del imaginario-imaginación por el imaginario-cultura. Sobre este punto, paralelamente a los trabajos bien conocidos de Lévi-Strauss sobre la «lógica concreta» subyacente al pensamiento mítico, son esencialmente las propuestas de Greimas y de Geninasca las que, en semiótica, indican la vía:

[...] ni los dioses ni los otros seres míticos son criaturas fantasiosas del imaginario: son medios figurativos que permiten hablar del hombre, del mundo y del orden cósmico (Greimas 1985: 12; subrayado nuestro).

El uso poético del lenguaje impone esta verdad, tan evidente en el mito como en el sueño, que las figuras del mundo son instrumentos del pensamiento [...]. Son el producto visible de operaciones subyacentes que traducen la manera como un sujeto competente se agencia objetos para pensar y para manipular (Geninasca 1981: 10; subrayado nuestro). 
En los trabajos de esos autores no se trata tanto, en efecto, de explorar un rincón $\mathrm{u}$ otro del imaginario-cultura como de dar cuenta, semióticamente, de esas «operaciones subyacentes» que juegan con «motivos figurativos» a fin de asegurar la inteligibilidad del tipo de producciones de carácter mitológico o poético que el imaginariocultura atribuye al imaginario-imaginación. En ese caso, aquí tenemos lo que podemos llamar una $\mathrm{j}$ «semiótica del imaginario»! ¡Et in Semiotica Imaginarium! ¿Y por qué no, en efecto? -Excepto que para que esa etiqueta tenga algún sentido, sería preciso dar a la palabra «imaginario» una significación completamente ajena a los usos que prevalecen hoy, como hemos visto a lo largo de este ensayo-.

Eso supondría que fuera aceptada la idea de un imaginario número tres, concebido ya no sustancialmente (como depósito memorial o como potencia errática), sino como un espacio puramente teórico: el de las operaciones semióticas que condicionan la producción y la captación del sentido figurativo. Lo que equivale a decir que un espacio semejante se confundiría prácticamente con el objeto mismo que la semiótica, en su conjunto, elige apostando a la posibilidad de una gramática de la significación. Hablar de una «semiótica del imaginario» equivaldría, en consecuencia, a usar una expresión no menos tautológica que aquella, tan en boga, de «semiótica de la cultura». Como ese género de etiquetas entraña, en el fondo, según creemos, más malentendidos que ventajas, en superficie, nosotros continuaremos dejándolo de lado.

\section{ANEXO \\ De quién - de qué Juego de sociedad}

Sobre una hoja de medidas $21 \times 29,7$ (papel canson), trazar tres columnas: a la izquierda, la columna de los Objetos; al centro, la columna de los Sujetos; a la derecha, la columna de las Descripciones.

El partido se juega en 400 tiempos. No hay límite al número de jugadores. El primer jugador escribe el nombre de un objeto de su elección en la columna de Objetos o, si prefiere, el nombre de un sujeto en la columna de Sujetos, luego, en cada una de las dos columnas, subraya un término de su elección.

El jugador siguiente describe el Objeto cuyo nombre acaba de ser subrayado, tal como se presenta en el imaginario del Sujeto cuyo nombre acaba de ser subrayado.

La descripción es sometida inmediatamente a la evaluación de los otros jugadores con un espíritu imparcial y según criterios rigurosamente objetivos. 
- descripciones que dan prueba de cultura: valor $=1$ punto;

- descripciones que dan prueba de imaginación: valor $=100$ puntos.

No está permitido recurrir a una enciclopedia.

Antes de pasar al tiempo siguiente, el jugador cuya descripción acaba de ser evaluada escribe, a su vez, el nombre de un objeto de su elección en la columna de Objetos o, si prefiere, el nombre de un sujeto en la columna de Sujetos; luego, en cada una de las dos columnas, subraya un término de su elección.

Y así continúa.

Ejemplo:

\begin{tabular}{|c|c|c|}
\hline $\begin{array}{c}\text { Columna } \\
\text { de los objetos } \\
0\end{array}$ & $\begin{array}{c}\text { Columna } \\
\text { de los sujetos } \\
S\end{array}$ & $\begin{array}{c}\text { Descripción } \\
\text { De } O \text { en el imaginario de } S\end{array}$ \\
\hline 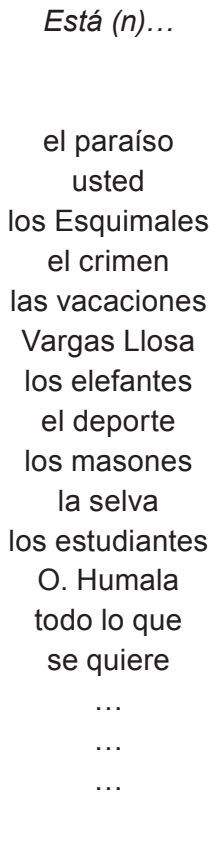 & $\begin{array}{c}\text { En el imaginario... } \\
\text { de los carceleros } \\
\text { de la clase obrera } \\
\text { del centro-izquierda } \\
\text { de los mutilados } \\
\text { de la novela negra } \\
\text { de los nómadas } \\
\text { de Borges } \\
\text { del gato } \\
\text { del presidente } \\
\text { de los esquimales } \\
\text { de todo el mundo } \\
\text { de los presos } \\
\text { de los obreros } \\
\text { de los médicos } \\
\text { de los barrenderos } \\
\ldots \\
\ldots\end{array}$ & \\
\hline
\end{tabular}




\section{Bibliografía}

Badiou, A. (2007). De quoi Sarkosy estil le nom? París: Nouvelles Editions Lignes.

Casetti, Frescesco (1999). "Cinéma et imaginaire», en Les théories du cinéma depuis 1945. París: Nathan.

Cohen, D. (1961). «Addad et ambigüité linguistique en arabe». Arabica, 8, 1.

Cyrano de Bergerac (1657). L'autre Monde. Histoire comique des etats et empires de la Lune, en Prévot (ed.). (1998). Libertines du XVIIe siècle. París: Gallimard (Pléiade).

Eco, Umberto (1992). Il secondo diario minimo. Milán: Bompiani.

Geninasca, Jacques (2010). «Praticare l'impertinenza», en Ceriani, G. (ed.). Impertinenze. Milán: Et al Edizzioni.

Geninasca, Jacques (1997). La parole littéraire. París: PUF, 1997. [En español: «El habla literaria». Lima. Prepublicación de circulación interna, Facultad de Comunicación de la Universidad de Lima].

Geninasca, Jacques (1993). «Les acquis et les projets». Nouveaux Actes Sémiotiques V, 25.

Geninasca, Jacques (1981). «Place du figuratif». Bulletin du Groupe de recherches sémio-linguistiques, La figurativité. París: CNRS 20.

Greimas, A. J. (1985). Des dieux et des hommes. Études de mythologie lithuanienne. París: PUF.
Greimas, A. J. (1966). Sémantique structurale. París: Larousse. [En español: Semántica estructural (1971). Madrid: Gredos].

Greimas, A. J. y J. Courtés (1979). Sémiotique. Dictionnaire raisonné de la théorie du langage. París: Hachette. [En español: Semiótica. Diccionario razonado de la teoría del lenguaje (1982). Madrid: Gredos, entrada «cultura»].

Greimas, A. J. y J. Fontanille (1991). Sémiotique des passions. Des états de choses aux états d'âme. París: Seuil.

Landowski, Eric (2011). «Bouillon de cultures», en Mohamed Bernoussi (dir.). De la Culture marocaine, une sémiotique. Actas del II Congreso de la Asociación Marroquí de Semiótica. Meknès: Presses de l'Université Moulay Ismaïl.

Landowski, Eric (2005). Les interactions risquées. Limoges: Pulim. [En italiano: Rischiare nelle interazioni. Milán: Franco Angeli, 2010; en español: Interacciones arriesgadas. Lima: Universidad de Lima, Fondo Editorial, 2009].

Landowski, Eric (2004). «Communautés de goût», en Passions sans nom, cáp. XI. París: PUF. [En español: «Pasiones sin nombre». Prepublicación de circulación interna, Facultad de Comunicación de la Universidad de Lima]. 
Landowski, Eric (1989). «L'opinion publique et ses porte-parole», «Vivre sa génération», en La societé reflechie, caps. I y II. París: Seuil. [En español: La sociedad figurada (1993), caps.
I y II. México: Fondo de Cultura Económica].

Semprini, Andrea (2000). CNN et la mondialisation de l'ímaginaire. París: CNRS.

Traducción: Óscar Quezada Macchiavello Título original: «De quoi l'imaginaire est-il le nom?», 2006. 